\title{
Porque Investir em Tecnologia no Setor Farmoquímico?
}

O atual panorama de desenvolvimento econômico aponta mais uma vez para o fortalecimento industrial, em especial nos seguimentos que tangem a produtos derivados da Química Fina e Farmoquímico (Tabela 1). Neste contexto o Brasil tem se consolidado como um membro ativo no cenário econômico mundial. Além do mercado consumidor, apresenta importante atividade nas exportações, garantindo um saldo positivo de 13 bilhões de dólares em nossa balança comercial para o período de janeiro a junho de 2011.

Tabela 1. Participação da Indústria Química nas exportações Brasileiras em 2011.

\begin{tabular}{|c|c|c|c|}
\hline \multicolumn{4}{|c|}{$\begin{array}{c}\text { Principais Produtos Exportados } \\
\text { Janeiro-Junho-2011 } \\
\text { US\$ Milhōes }\end{array}$} \\
\hline & yator & zoivino & Part of \\
\hline 1-Minerios & 19.420 & 87.0 & 16,4 \\
\hline 2- Petrobleo e combustivets & 14.861 & 32,1 & 12.6 \\
\hline 3-Complexo soja & 12.717 & 13,0 & 10,7 \\
\hline 4-Material de transporte & 11.827 & 24,2 & 10,0 \\
\hline 5-Produtos metatôrgicos & 8. 1868 & 48,5 & 7,5 \\
\hline 6-Quimicos & 7.563 & 18,8 & 6,4 \\
\hline 7-Carnes & 7.454 & 18,3 & 6.3 \\
\hline 8- Açucar e etanol & 5.797 & 11,5 & 4,9 \\
\hline 9 -Miqqs, e equipannentas & 4.758 & 30,7 & 4,0 \\
\hline 10 - cated & 3.942 & 54,2 & 3,3 \\
\hline 11- Papel e celuiose & 3.560 & 2,1 & 3,0 \\
\hline 12 - Equiparventos eiétricas & 2.187 & $-3,4$ & 1,8 \\
\hline 13 - Calpades e couru & 1.870 & 6,5 & 1,6 \\
\hline 14 - Methis e Podras Prociosos & 1.348 & 37,1 & 1,1 \\
\hline 15 - Fumb e Sucedaineos & 1.162 & $-0,7$ & 1,0 \\
\hline
\end{tabular}

Apesar desses resultados serem dignos de comemoração, os dados da Tabela 2 mostram que ainda houve uma intensa participação da Indústria Farmacêutica Nacional nas importações realizadas durante o ano de 2011. A contribuição nesses números se deve, em grande parte, à importação dos Ingredientes Farmacêuticamente Ativos (IFA's) necessários à produção nacional dos medicamentos. A análise desta situação nos leva a concluir que o crescimento do setor Farmoquímico e o consequente aumento na produção nacional dos IFA’s, além de reduzir a contribuição do setor Farmacêutico para as importações, têm o potencial de promover um significativo incremento em nossas exportações de produtos químicos, em especial aqueles com maior valor agregado, fato que contribuiria ainda mais para um superávit em nossa balança comercial.

Tabela 2. Participação dos Produtos Químicos e Farmacêuticos nas importações do Brasil em 2011.

\begin{tabular}{|c|c|c|c|}
\hline \multicolumn{4}{|c|}{$\begin{array}{c}\text { Principais Produtos Importados } \\
\text { Janeiro-Junho- } 2011 \\
\text { US\$ Milhōes }\end{array}$} \\
\hline & Valor & axitiso & Part \& \\
\hline 1-Comberstiveis el uabriticantes & 19.183 & 36,4 & 19,2 \\
\hline 2- Equip Mocinicos & 15.984 & 29,7 & 15,2 \\
\hline 3- Equife altricos a Eietronicos & 22.592 & 25,7 & 12,0 \\
\hline 4- huatomineis e partos & 10.063 & 32,9 & 9,6 \\
\hline 5- guimims oroan e thoeguivices & 5.565 & 23,3 & 5,3 \\
\hline 6-Phindicase Obras & 3.651 & 29,0 & 3,7 \\
\hline 7-Fortilizantes & 3.640 & 102,2 & 3,5 \\
\hline a - Femo, Asco e Obras & 3.463 & 0,3 & 3,3 \\
\hline 9- Parmecluticis & 3.083 & $-3,8$ & 2,9 \\
\hline 10 - Inetr. ditca e Procisto & 3.023 & 2,6 & 2,9 \\
\hline 11- comracie a obres & 2.446 & 38,3 & 2,3 \\
\hline 12 - Coesis e probutes de moagen & 1.535 & 11,0 & 1,5 \\
\hline 13 -colarte sus obras & 1.497 & 32,7 & 1,4 \\
\hline 14- Nevenanes e prectas & 1.186 & 21,1 & 1,1 \\
\hline 15 - Flansen, o Forras, Sintet a Aric & 1.153 & 28,1 & 1,1 \\
\hline
\end{tabular}

Em face da atual política nacional, é possível observar algumas ações do Governo Brasileiro para que haja um fortalecimento industrial, em especial nos seguimentos de química fina e farmoquímica. Este fato pode ser claramente observado à luz de três ações governamentais recentes:

i. Chamadas públicas do FINEP (Financiadora de Estudos e Projetos) para subvenções econômica de projetos privados relacionado à descoberta de novos IFA's e desenvolvimento de processos industriais de IFA's estratégicos ;

ii. Licença Compulsória do Medicamento Efavirenz;

iii.Parceiras Público-Privadas (PPP) para produção nacional de IFA's e medicamentos estratégicos. 
Em 2006 a FINEP, vinculada ao Ministério da Ciência e Tecnologia (MCT), publicou a primeira chamada pública com o intuito de capacitar as empresas nacionais na descoberta de novas drogas e no desenvolvimento de processos industriais de preparação das mesmas, em especial drogas utilizadas no tratamento de HIV e HCV (Hepatite C Viral). A título de curiosidade, vale ressaltar que a FINEP concedeu, nesta modalidade de financiamento, valores que giraram em torno de um terço do valor total investido no projeto submetido pela empresa contemplada.

Em maio de 2007, a Presidência da República, através do decreto 6.108, decretou a licença compulsória para comercialização do medicamento Efavirenz, cuja patente pertence à Merck Sharp \& Dome. Por meio dessa medida ficou permitido, do ponto de vista legal, a produção local não somente da forma farmacêutica, mas também do ingrediente farmaceuticamente ativo (IFA). A partir desse precedente, houve uma corrida de empresas nacionais para se capacitarem na síntese deste IFA, uma vez que não se consumou o contrato entre o Ministério da Saúde (MS) e a empresa detentora da patente, mesmo após a declaração de "interesse público" do MS no Efavirenz por meio da portaria 886 de 24 de abril de 2007. Em negociações anteriores, os medicamentos Nelfinavir (da Roche) e a combinação de Lopinavir e Ritonavir (ARV Kaletra da Abbott) também tiveram seu "interesse público” decretados com objetivo da manutenção do Programa DST/AIDS do MS.

A declaração de "interesse público" e licenças compulsórias sobre medicamentos são temas de natureza controversa. Tal ação, quando analisada de forma isolada, leva a um desconforto uma vez que esta limita o direito de uma empresa de usufruir dos lucros oriundos desta tecnologia a ela garantido pela concessão de uma carta patente. Tal fato se torna ainda mais questionável quando são apresentadas as somas investidas pela empresa neste desenvolvimento. Todavia, além de trazer consigo a manutenção de políticas de saúde pública estratégicas ao Brasil, a declaração da licença compulsória aqui ocorrida impulsionou as empresas nacionais envolvidas na produção do Efavirenz a investirem na preparação de suas plantas produtivas e na capacitação de suas equipes de Pesquisa, Desenvolvimento e Inovação (PD\&I), Produção e Qualidade para que todos os requisitos de qualidade exigidos por nossa legislação viessem a ser atendidos em suas produções.

Em dezembro de 2008, o Ministério da Saúde resolveu, por meio da portaria 3.031:

“Art. $1^{\circ}$ Estabelecer que os Laboratórios Oficiais de produção de medicamentos, em suas licitações, devam dar preferência à aquisição dos ingredientes farmacêuticos ativos necessários à sua linha de produção de empresas que produzam essas matérias-primas no País.

Art. $2^{\circ}$ Quando houver mais de um fornecedor que atenda às condições estabelecidas pelo artigo $1^{\circ}$ desta Portaria, os laboratórios oficiais de produção de medicamentos deverão levar em conta, no processo licitatório, o grau de verticalização da produção no País, apresentado pelos fornecedores".

Como resultado desta portaria, iniciou-se o estabelecimento das Parcerias Público-Privadas (PPP) que objetivam a produção nacional, tanto do IFA quanto da forma farmacêutica para medicamentos. Entre 2009 e 2011 foram estabelecidas 28 PPP para produção de 29 medicamentos estratégicos destinados ao tratamento de doenças como AIDS, tuberculose, asma e colesterol alto. Os IFA's motivadores destas PPP têm sido cuidadosamente selecionados dentre os 80 medicamentos estratégicos encontrados na portaria $\mathrm{n}^{\circ} 1.284$, de 26 de maio de 2010 , do Ministério da Saúde, atualização da portaria nº 978, de 16 de maio de 2008 do mesmo ministério.

Todas estas ações deixam claras as intenções do Governo Brasileiro sobre o fortalecimento do setor Farmoquímico e são, certamente, um incentivo para que empresas nacionais iniciem ou fortaleçam os investimentos neste segmento de nossa Indústria Química.

Na medida em que tal cenário foi se estabelecendo, os órgãos regulatórios também aperfeiçoaram a legislação que trata de insumos para o setor farmacêutico bem como a legislação sobre os medicamentos propriamente ditos. Em 13 de setembro de 2005, o MS publicou a (Resolução de Diretoria Colegiada) RDC 248, legislação específica para a concessão do certificado de Boas Prática de Fabricação (BPF) para empresas envolvidas na produção e fracionamento para revenda de insumos farmacêuticos, incluindo os IFA's.

Em 18 de novembro de 2009 o MS publicou a RDC 
57/2009 e a IN 15/2009 que regulamentam o registro de 20 IFA's estratégicos para as políticas nacionais de medicamentos deste ministério:

1. Ciclosporina

2. Clozapina

3. Cloridrato de clindamicina

4. Ciclofosfamida

5. Ciprofloxacino

6. Metotrexato

7. Carbamazepina

8. Carbonato de lítio

9. Fenitoína

10. Fenitoína sódica

11. Lamivudina

12. Penicilamina

13. Tiabendazol

14. Efavirenz

15. Nevirapina

16. Rifampicina

17. Ritonavir

18. Zidovudina

19. Aciclovir

20. Ampicilina

Nesta regulamentação, se faz necessária apresentação de informações gerais sobre a substância para qual se requisita o registro (Nomenclatura: Denominação Comum Brasileira, ou na sua falta, Denominação Comum Internacional, número CAS, nome químico, sinonímia com referência completa, fórmula molecular e estrutural, peso molecular, forma física e outras propriedades físico químicas como $\mathrm{pH}$, solubilidade, ponto de fusão e ponto ebulição, tamanho da partícula, estruturas cristalina, amorfa e solvatos) assim como informações sobre o processo de fabricação e controle de qualidade do IFA (matérias primas, solventes, catalisadores, especificações das matérias-primas e materiais de embalagem, escala de produção, rendimento, equipamentos, condições de operação, controles em processo, etapas críticas incluindo respectivos testes e critérios de aceitação, fluxograma do processo produtivo com indicação da formação de intermediários e de possíveis impurezas).

Duas questões importantes que são levantadas na legislação sobre BPF e registro de insumos dizem respeito ao perfil de impureza e à caracterização do estado sólido dos IFA's. O perfil de impurezas deve ser cuidadosamente investigado por meio do controle de qualidade dos materiais de partida empregados no processo de síntese do IFA, estudos de degradação forçada e estudos de estabilidade do IFA. Todas estas informações são fundamentais para que se desenvolva uma metodologia de análise que seja indicadora de qualidade deste produto.

Desde 1996 o estado sólido dos IFA's tem recebido uma especial atenção das empresas e dos órgãos regulatório. Nesta ocasião, o surgimento de uma nova forma cristalina menos solúvel do antiretroviral Ritonavir promoveu o recall do medicamento Norvir® da Abbot. Esta forma cristalina, 50\% menos solúvel em etanol que a originalmente utilizada na fabricação das capsulas gelatinosas do $\operatorname{Norvir}{ }^{\circledR}$, levou à precipitação do IFA no interior das capsulas e redução da eficiência deste medicamento. Estas novas formas cristalinas, denominadas polimorfos, devem ser, de acordo com a legislação brasileira, investigadas e sua formação deve ser controlada durante o processo de produção e armazenamento dos IFA's, uma vez que polimorfos tem o potencial de apresentar diferenças significativas em propriedades físico-químicas importantes para a eficiência de um medicamento.

Sob esse prisma, a constante busca por processos industriais eficientes para produção dos IFA's que atendam a legislação brasileira e mundial, bem como as exigências de qualidade do mercado tem impulsionado as empresas a investir na consolidação de seus setores voltados à PD\&I por meio da atualização tecnológica dos laboratórios onde essas equipes executam tais funções, bem como pela contratação de profissionais com alto grau de especialização em domínios estratégicos. Diferentemente do pensamento de muitos, um processo industrial utilizado na síntese de alguma substância 
orgânica, por exemplo, não é a simples realização de reações químicas dentro de recipientes com volumes que comportem quantidades maiores dos insumos originalmente empregados no desenvolvimento em escala laboratorial desta substância. A transposição de escala compreende uma sucessão de eventos passíveis de acontecer e muitos deles são de difícil visualização em escala de laboratório, tais como demandas de troca de calor, gradientes de temperatura (hot spots), falta de homogeneidade como característica de agitação ineficiente. Tais eventos são indesejáveis e causam, durante o processo de produção de um IFA, a formação de impurezas químicas e físicas (polimorfos), geração de resíduos (efluentes) com elevada toxicidade, ausência de homogeneidade entre lotes e descontrole térmico.

Frente a todos estes desafios, cabe uma pergunta: Nossas instituições de ensino têm capacitado profissionais para atender as demandas deste setor? O Programa REUNI ampliou o número de cursos de graduação em química, química tecnológica e engenharia química nas Instituições de Ensino Superior (IES's), fato que trará em breve um expressivo aumento no número de profissionais necessários ao desenvolvimento do Setor Farmoquímico Nacional. Os últimos anos têm registrado um crescente número de profissionais da Química egressando de programas de pós-graduação com o título de mestre ou doutor em áreas como Química Analítica, Química Orgânica e Química Tecnológica, todas estas fundamentais em um grupo de PD\&I de uma empresa Farmoquímica. A Escola Superior em Síntese Orgânica, iniciativa da Sociedade Brasileira de Química, cuja quarta edição foi realizada este ano no campus da Universidade de São Paulo da cidade de São Carlos, tem sido um ambiente frutífero para a interação entre professores das IES, alunos de pós-graduação e profissionais da Indústria Química. Assuntos como empreendedorismo, aspectos modernos de síntese orgânica, novas tecnologias para execução de reações químicas e desafios relacionados ao cotidiano de um setor de PD\&I de uma empresa são compartilhados e servem de estímulo para as novas gerações de profissionais da Química vislumbrarem meios de interagir ou ingressar neste setor produtivo.

Com base nas informações discutidas, fica difícil ignorar o fato de que o Brasil encontra-se em um momento privilegiado para setor Farmoquímico. Ações governamentais têm impulsionado iniciativas do setor privado a investir na consolidação e crescimento dos setores de PD\&I de empresas Farmoquímicas. Este fato, além de fortalecer as políticas públicas do Ministério da Saúde, ajuda a reduzir a contribuição do setor Farmacêutico nas importações, situação que viabiliza outros investimentos governamentais nestas ações de incentivo. O crescente número de profissionais da Química com qualificação para atuar nestes grupos de PD\&I dão suporte a este crescimento e contribuem para que os processos industriais ali desenvolvidos atendam, além da competitividade no custo, os requisitos de qualidade, segurança e sustentabilidade que nossa legislação exige.

\section{Angelo H. L. Machado' \& Wender A. Silva ${ }^{2 *}$}

${ }^{1}$ Grupo de Tecnologia em Síntese Orgânica do Laboratório de Isolamento e Transformação de Moléculas Orgânicas, Instituto de Química, Universidade de Brasília, CP 4478, Brasília.

${ }^{2}$ Laboratório de Planejamento e Síntese de Compostos Ativos, Instituto de Química, Universidade de Brasília, CP 4478, Brasília.

*e-mails: wender@unb.br 